\title{
PITUNGGUA SEBAGAI KONSEP GERAK TRADISI DALAM TARI BUAI-BUAI DI PERGURUAN SINGO BARANTAI LUBUAK LINTAH PADANG
}

\author{
Rosi Afriyanti, Nursyirwan, dan Sahrul N \\ Pascasarjana Institut Seni Indonesia Padangpanjang, Indonesia \\ Email: redaksiMAPJ@gmail.com, No.Hp: 085263853922
}

\begin{abstract}
Buai-Buai dance originates from Pesisir Selatan in Singo Barantai community, Lubuak Lintah, Padang. Buai-Buai dance is danced with a number of knockers of 2 (two), 4 (four) and so on. This dance is a procession of farmers planting events while adjusting children. This dance is performed at the batagak penghulu, urak balabek, and wedding events in the Pauh Sembilan society. Buai-Buai dance originates from the phenomenon of the story of farmers growing crops. The purpose of this research is to find out in depth about the structure and aesthetics of the Buai-Buai in Singo Barantai College, Lubuak Lintah, Padang. The method used in this study is a qualitative method, and the theory used to dissect the Buai-Buai dance phenomenon is the Djelantik aesthetic theory. in the BuaiBuai dance movement, it contains structures and aesthetics associated with the procession or events of farmers farming in the Pauah Sembilan society.
\end{abstract}

Keywords: Buai-Buai Dance, Batagak Penghulu, Aesthetics and Lubuk Lintah.

\begin{abstract}
ABSTRAK
Tari Buai-Buai berasal dari Daerah Pesisir Selatan yang berada di Perguruan Singo Barantai Kecamatan Lubuak Lintah, Padang. Tari Buai-Buai ditarikan dengan jumlah penaru 2 (dua), 4 (empat) dan seterusnya. Tari ini merupakan prosesi peristiwa petani bercocok tanam sambil membuaikan anak. tari ini dilakukan pada acara batagak penghulu, urak balabek, hingga acara pernikahan di masyarakat Pauh Sembilan. Tari Buai-Buai berasal dari fenomena kisah petani bercocok tanam. Tujuan dari penelitian ini adalah untuk mengetahui secara mendalam tentang struktur dan estetika tari Buai-Buai di Perguruan Singo Barantai, Lubuak Lintah, Padang. adapun metode yang digunakan dalam penelitian ini adalah metode kualitatif, dan teori yang digunakan untuk membedah fenomena tari Buai-Buai adalah teori estetika Djelantik. dalam gerak tari Buai-Buai, mengandung struktur dan estetika yang terkait dengan prosesi atau peristiwa petani bercocok tanam di masyarakat Pauah Sembilan.
\end{abstract}

Kata Kunci: Tari Buai-Buai, Batagak Penghulu, Estetika dan Lubuk Lintah. 


\section{PENDAHULUAN}

Sumatera Barat dengan ibu kota Kota Padang terdiri dari 11 Kecamatan dan 104 Kelurahan. Lubuk Lintah adalah salah satu kelurahan di Kecamatan Kuranji, kecamatan ini meliputi Nagari Pauh IX yang terdiri dari sembilan tepian yaitu Ampang, Anduring, Gunung Sariak, Kalumbuak, Korong Gadang, Kuranji, Lubuk Lintah, Pasar Ambacang, dan Sungai Sapih. Di kelurahan Lubuk Lintah berdiri salah satu perguruan beladiri yaitu Singo Barantai, dan dalam perguruan tersebut berkembanglah satu tarian tradisional Minangkabau yakni tari Buai-Buai.

Tari Buai-Buai ini lahir kira-kira pada abad 18 Masehi. Tarian yang berkembang di Pesisir Selatan ini sampai di Kota Padang dibawa oleh seorang tokoh yang sampai sekarang namanya tidak diketahui. Ciri khas dari tarian ini adalah gerak buai-buai, gerak rantak kudo, gerak nandi-nandi, dan gerak tikam jajak. gerakan lainnya adalah gerakan-gerakan orang pergi ke sawah, dari gerakan mencangkul, menuai padi sampai menarik padi sebagai hasil panen. tarian ini diiringi oleh gendang, saluang pauah, pupuik batang padi, talempong dan dendang.

Ciri lain dari tarian ini adalah para penari meletakkan galeta atau timbala di atas kepala mereka dan menggunakannya sambil menari. Galeta atau timbala adalah suatu alat serupa kendi terbuat dari kaca yang diletakkan di atas kepala ketika menari, sehingga para penari harus bisa menyeimbangkan gerakannya agar galeta/ timbala (gelas) tersebut tidak terjatuh.
Selain galeta atau timbala, para penari kadang menggunakan dama, yaitu sebuah lentera yang terbuat dari bahan kaleng.

Tari Buai-Buai digunakan untuk acara adat tradisi seperti acara urak balabek (upacara pengangkatan guru Silat khusus di Kota Padang), batagak penghulu dan acara pernikahan. Awalnya tari Buai-Buai ditarikan oleh kaum laki-laki berjumlah genap yaitu dua, empat dan seterusnya, karena tarian ini sering ditampilkan pada malam hari untuk hiburan anak nagari yang sedang berjaga dan berkumpul di surau (mushala). Sedangkan perempuan tidak boleh keluar di waktu malam hari, hal ini sesuai dengan adat istiadat orang perempuan di Minangkabau (wawancara dengan Irwandi, 15 September 2018).

Berpedoman pada paparan di atas, jelas bahwa tari Buai-Buai memiliki nilai estetika yang tinggi. Hal ini dikarenakan estetika tidah hanya menyelidiki produk-produk seni, melainkan juga prosesnya serta kemampuan-kemampuan yang terlibat dalam penciptaan, penggunaan, penikmatan, penghayatan (apresiasi), serta penilaiannya (Soedarsono, 1977).

Dalam masa sekarang, perkembangan keilmuan tentang estetika telah meluas, tidak sebatas pada artifak yang disepakati sebagai suatu karya seni, tetapi pada artifak yang mengandung makna. Estetika juga mengkaji hal lain seperti fenomena alam, karya seni, karya desain, filsafat seni, proses kreatifitas (Sachari, 2002: 4). 
Pandangan mengenai estetika di atas, mengalami pergeseran disetiap waktu, sejalan dengan pergeseran konsep estetika setiap zaman. Pandangan bahwa estetika hanya mengkaji segala sesuatu yang indah (cantik dan gaya seni) telah lama dikoreksi, karena terdapat kencendrungan karya-karya seni modern tidak lagi menawarkan kecantikan akan tetapi lebih kearah makna dan aksi mental.

Dikaitkan dengan karya seni tari, keindahan sesuatu yang memberikan kepuasan bathin, maka semua gerak yang memberikan kepuasaan bathin disebut indah. Tak hanya gerak-gerak yang indah saja, akan tetapi juga gerakan yang keras, kasar, kuat, penuh dengan tekanan-tekanan serta aneh sekalipun dapat dikatakan gerak yang indah. Dengan demikian, keindahan tidak terbatas pada sesuatu yang menyenangkan, tetapi juga sesuatu yang mendebarkan, menakutkan, menyedihkan, dan menggelisahkan (RM Soedarsono, 1977).

Pada wilayah Minangkabau masih banyak ditemui tari tradisional yang masih mempertahankan pola-pola budaya tradisi dalam penyajian dan aktivitas tari tersebut. Tari tradisional Minangkabau yang berkembang menggambarkan nilai-nilai tradisi setempat dengan keindahan yang khas. Nilai keindahan tersebut dinamakan dengan istilah estetika. Menurut Indrayuda (2000: 12) estetika tari Minangkabau terletak pada bentuk gerak yang agresif, gerakan patah-patah, lintasan dan dinamika gerak. Selain itu, estetika tarian Minangkabau juga terletak pada gaya tari yang berakar pada ketangkasan dan kewaspadaan.

Berdasarkan observasi awal yang peneliti lakukan, keberadaan dan perkembangan sekaligus proses latihan tari Buai-Buai yang dilakukan di Perguruan Singo Barantai berlangsung dengan baik. Beberapa pertunjukan (penampilan) telah dilakukan oleh Perguruan Singo Barantai baik bersifat lokal ataupun Internasional. Hal ini menandakan tari tradisional Minangkabau, khususnya tari Buai-Buai mendapatkan pandangan khusus dari nilai estetika di mata masyarakat luas serta mampu menjadikan tari Buai-Buai sebagai destinasi Pariwisata di Sumatera Barat, untuk itu peneliti sangat antusias untuk meneliti estetika tari Buai-Buai.

\section{METODE PENCIPTAAN}

Metode penelitian ini dilakukan secara kualitatif. Metode Kualitatif adalah prosedur penelitian yang menghasilkan data deskriptif ucapan atau tulisan dan perilaku yang dapat diamati dari orang (subjek) itu sendiri (Arief Furchan, 1992: 21-22). Objek yang diteliti adalah Tari Buai-Buai di Perguruan Singo Barantai Lubuk Lintah Padang yang menghasilkan data deskriptif kemudian dianalisis sesuai dengan kajian. Penelitian ini di lakukan dengan tahapan pengumpulan data, pengolahan data, Analisis data. Pengumpulan data dilakukan dengan tahapan:

\subsection{Rancangan Penelitian}

Secara umum rancangan penelitian diartikan sebagai seluruh proses perancangan dan pelaksanaan suatu 
riset, dalam arti sempit dan khusus berarti prosedur pengumpulan data dan analisis data (Supranto, 2003: 54). Rancangan Penelitian adalah suatu pengaturan syarat-syarat untuk mengontrol pengumpulan data dalam suatu penelitian sedemikian rupa dengan tujuan untuk mengombinasi segala informasi yang relevan sesuai dengan tujuan penelitian.

Terkait dengan hal di atas, pengumpulan data yang dilakukan peneliti yaitu menggunakan observasi, wawancara dan dokumentasi. Sumber data yang di dapat dari observasi dan wawancara yang dihimpum sejumlah informan yang terkait dengan objek penelitian yaitu tari Buai-Buai di Perguruan Singo Barantai Lubuk Lintah Padang.

\subsection{Menentukan Lokasi dan Topik Penelitian}

Sebelum melakukan penelitian terlebih dahulu mengetahui tempat/ Nagari Penelitian. Nagari yang diambil peneliti adalah di Nagari Pauh IX Perguruan Singo Barantai Lubuk Lintah Padang. Setelah itu menentukan objek dari apa yang akan diteliti yaitu tari Buai-Buai yang ada di Perguruan Singo Barantai Lubuk Lintah Padang.

\subsection{Instrumen Penelitian}

Instrumen dalam penelitian ini dilakukan wawancara yang mengacu pada objek tari Buai-Buai, dan peneliti dibantu dengan instrument pendukung seperti alat tulis, kamera foto, handycam dan flashdisk.

\subsection{Jenis dan Sumber Data}

\section{a. Jenis Data}

Jenis data dalam penelitian ini bersifat kualitatif. Jenis data dalam penelitian ini terdiri data primer dan data sekunder. Data primer adalah data dalam bentuk verbal atau kata-kata yang diucapkan secara lisan, gerak-gerik atau perilaku yang dilakukan oleh subjek yang dapat dipercaya, dalam hal ini adalah informan yang berkenaan dengan variable (Arikunto, 2013).

Data primer dalam penelitian ini diperoleh melalui hasil wawancara terhadap informan yang dianggap berpotensi dalam memberikan informasi yang relevan di lapangan, seperti Irwandi (pelatih tari Buai-Buai), Meli Merdeka Sari dan Meri Rhamanelly (Penari), Afrijhon (seniman), Mirmaneli (Tokoh Masyarakat). Sedangkan data sekunder adalah data yang diperoleh dari dokumen-dokumen grafis (tabel, catatan, foto, film, rekaman video dan benda-benda lain yang dapat memperkaya data primer (Arikunto, 2013). Data sekunder dalam penelitian ini adalah buku tentang estetika, seni tari, filsafat seni, dan buku-buku yang relevan dengan objek penelitian.

b. Sumber Data

Sumber data adalah segala sesuatu yang dapat memberikan informasi mengenai data. Menurut Arikunto (2013: 172) sumber data adalah subjek dari mana data dapat diperoleh. Lofland dan Lofland mengungkapkan bahwa sumber data dalam penelitian kualitatif 
adalah kata-kata dan tindakan selebihnya adalah data tambahan seperti dokumentasi dan lain-lain (Moleong, 2007: 157).

Moleong (2007: 157-162) menjelaskan bahwa dalam penelitian kualitatif, data yang bisa diambil sebagai komponen penarikan kesimpulan antara lain:(1) Kata-kata dan tindakan, kata-kata dan tindakan orang-orang yang diamati atau diwawancarai merupakan sumber data utama, sumber data ini dapat dicatat melalui catatan tertulis, rekaman, voice recording, dan foto. Data yang berasal dari kata-kata dan tindakan sumber data mulanya dikumpulkan secara acak sebanyak mungkin tanpa harus dibatasi oleh fokus masalah. Setelah data terkumpul kemudian masuk dalam tahap data collecting sebelum direduksi untuk dipilah data mana yang memiliki hubungan keterkaitan langsung dengan fokus penelitian. (2) Sumber data tertulis Sumber tertulis sebagai sumber data kedua setelah katakata dan tindakan. Dilihat dari segi sumber data, bahan tambahan yang berasal dari sumber tertulis dapat dibagi atas sumber buku dan majalah ilmiah, sumber dari arsip, dokumen pribadi, dan dokumen resmi. (3) Foto Menurut Bogdan dan Biklen (1982) dalam Moleong (2007: 160) foto menghasilkan data deskriptif yang cukup berharga dan sering digunakan untuk menelaah segi-segi subjektif dan hasilnya sering dianalisis secara induktif. Ada dua kategori foto yang dapat dimanfaatkan dalam penelitian kualitatif, yaitu foto yang dihasilkan orang dan foto yang dihasilkan oleh peneliti.

\subsection{Teknik Pengumpulan Data}

a. Observasi

Menurut Sukmadinata (2009: 220) observasi atau pengamatan merupakan suatu teknik atau cara mengumpulkan data dengan jalan mengadakan pengamatan terhadap kegiatan yang sedang berlangsung. Dalam menggunakan metode observasi, cara yang paling efektif adalah melengkapi dengan format dan blangko pengamatan sebagai instrumen. Format yang disusun berisi item-item tentang kejadian atau tingkah laku yang digambarkan akan terjadi (Arikunto, 2013: 272).

Peneliti akan mengadakan observasi dimana peneliti mengamati secara langsung keadaan sebenarnya dalam tempat penelitian. Menurut Spradley dalam Sugiyono (2014: 313), objek penelitian kualitatif yang diobservasi terdiri dari 3 komponen, yaitu: (1) Place, adalah tempat dimana interaksi dalam situasi sosial sedang berlangsung; (2) Actor, pelaku atau orang-orang yang sedang memainkan peran tertentu; dan (3) Activity, kegiatan yang dilakukan oleh aktor dalam situasi sosial yang sedang berlangsung, seperti kegiatan belajar, interaksi sosial, maupun kegiatan yang berhubungan dengan penelitian lainnya. Dalam hal ini peneliti akan mengobservasi proses pelaksanaan tari Buai-Buai. 
b. Wawancara

Wawancara adalah percakapan dengan maksud tertentu. Percakapan itu dilakukan oleh dua pihak, yaitu pewawancara (interviewer) yang mengajukan pertanyaan dan terwawancara (interviewer) yang memberikan jawaban atas pertanyaan itu (Moleong, 2007: 186). Esterberg (2002) dalam Sugiyono (2014: 317) mengemukakan beberapa macam wawancara, yaitu wawancara terstruktur, semi terstruktur, dan tidak terstruktur. Dalam penelitian ini teknik wawancara yang digunakan yaitu wawancara terstruktur. Menurut Sugiyono (2014: 189) wawancara terstruktur digunakan sebagai teknik pengumpulan data, nilai penulis atau pengumpul data telah mengetahui dengan pasti tentang informasi apa yang diperoleh. Oleh karena itu, dalam melakukan wawancara, pengumpul data telah menyiapkan instrument penelitian berupa pertanyaan-pertanyaan tertulis yang alternatif jawabannya pun telah disiapkan. Moleong (2007: 190) juga menjelaskan bahwa wawancara terstruktur adalah wawancara yang pewawancaranya menetapkan sendiri masalah dan pertanyaan-pertanyaan yang akan diajukan.

Pengumpulan data dengan teknik wawancara terstruktur dilaksanakan secara terencana dengan berpedoman kepada daftar pertanyaan yang sudah dipersiapkan sebelumnya, untuk mendapatkan informasi dari responden. Penulis akan melakukan wawancara kepada pelatih, penari, seniman dan tokoh masyarakat di kelurahan Lubuak Lintah.

\section{b. Dokumentasi}

Penelitian ini juga merujuk data dari bahan berupa dokumentasi seperti teks berupa bacaan, rekaman audio visual (data yang diperoleh dari foto, rekaman, buku) dan catatan yang berkaitan dengan objek penelitian.

\subsection{Teknik Analisis Data}

Analisis data kualitatif menurut Bogdan dan Bliken (1982) dalam Moleong (2007: 248) merupakan upaya yang dilakukan dengan jalan bekerja dengan data, mengorganisasi data, memilah-milah menjadi satuan yang dapat dikelola, menyintesisnya, mencari dan menemukan pola, menemukan apa yang penting dan apa yang dipelajari, dan memutuskan apa yang diceritakan kepada orang lain. Sieddel (1998) dalam Moleong (2007: 248) menjabarkan proses analisis data kualitatif sebagai berikut: (1) Mencatat apapun data yang didapat dalam bentuk catatan lapangan, dengan begitu sumber datanya dapat ditelusuri apabila membutuhkan data tersebut kembali. (2) Mengumpulkan, memilah-milah, mengklasifikasikan, mensintesiskan, membuat ikhtisar, dan membuat indeksnya. (3) Berpikir, dengan jalan membuat agar kategori data itu mempunyai makna, mencari dan menemukan pola dan hubunganhubungan, dan membuat temuantemuan umum. Selanjutnya menurut Mc. Drury (1999) dalam Moleong, (2007: 
248) tahapan analisis data kualitatif sebagai berikut: (1) Membaca/ mempelajari data, menandai kata-kata kunci dan gagasan yang ada dalam data. (2) Mempelajari kata-kata kunci itu, berupaya menemukan tema-tema yang berasal dari data. (3) Menuliskan "model" yang ditemukan. (4) Koding yang telah dilakukan. Dalam penelitian kualitatif, data diperoleh dari berbagai sumber dengan menggunakan teknik pengumpulan data yang bermacammacam (triangulasi) dan dilakukan secara terus menerus hingga datanya jenuh, namun analisis data dalam penelitian kualitatif lebih difokuskan selama proses di lapangan bersamaan dengan pengumpulkan data (Sugiyono, 2014: 331).

Teknik analisis yang digunakan penulis adalah teknik analisis Miles and Huberman (1984), teknik ini dilakukukan secara interaktif dan berlangsung secara sampai tuntas, sehingga datanya sudah jenuh (Sugiyono, 2014: 334). Teknik analisis data Miles dan Huberman dilakukukan secara terus menerus dan lebih difokuskan selama proses di lapangan bersamaan dengan pengumpulan data. Teknik ini dilakukan secara interaktif dan terus menerus sampai datanya jenuh. Aktivitas dalam analisis data kualitatif menurut Miles dan Huberman (2014: 20).

\section{PEMBAHASAN}

Tari Buai-Buai yang berkembang di daerah Lubuk Lintah, merupakan perluasan dan perkembangan dari daerah aslinya yaitu kanagarian Pauh. Di Lubuk Lintah gerakan dasar Tari BuaiBuai hanya memiliki dua gerakan, yakni gerakan dasar Buai-Buai dan gerakan dasar rantak kudo. Gerakan Buai-Buai merupakan cerminan atau pragmen gerak mengasuh anak. Gerak ini menjadi dasar gerak silat yang dilaksanakan dengan cara kaki kanan melangkah kekanan diikuti kaki kiri membentuk pitunggua. Tangan kiri melengkung di depan badan dan tangan kanan melengkung di sisi badan kanan. Kesan yang ditonjolkan pada gerakan ini adalah menghindari serangan dan mengambil ancang-ancang untuk melaksanakan suatu aksi.

Gerakan kedua adalah gerakan rantak kudo, gerakan ini mempunyai karakteristik dinamika gerak dengan cara kaki kiri menghentak dibelakang kaki kanan sementara kaki kanan terangkat, dan sebaliknya ketika kaki kiri menghentak di belakang kaki kanan kaki kiri terangkat. Sedangkan kedua tangan melakukan gerakan kesamping kiri dan kanan di depan dada. Dinamika gerak ini mencerminkan gerak tertatihtatih mengemban beban

Analisis struktur gerak tari BuaiBuai mengaju pada tulisan Ben Soeharto, dalam pengamatan Tari Gambyong melalui pendekatan struktural dalam bidang linguistik. Kertas kerja yang disajikan dalam temu wicara etnomusikologi III di Medan, 2 s/d 5 Februari 1987). Analisis struktur gerak tari Buai-Buai, diantaranya:

\subsection{Gugus Gerak}

Gugus gerak merupakan sekelompok kalimat gerak atas dasar pembagian dari pola iringan. Suharto (1983) memaparkan bahwa gerak adalah kumpulan beberapa kalimat yang 
saling berkaitan karena mempunyai ciri tertentu yang disebut paragraf dalam bahasa. Gugus gerak yang dimaksudkan sebagai penyebutan kalimat yang saling berkaitan dan mempunyai ciri-ciri tertentu serta keutuhan sebagai kelompok, baik dari segi gerak maupun iringan (Suharto,1983:18).

Untuk lebih jelasnya gugus dapat di deskripsikan pada gerak Buai-Buai yaitu dengan kaki kiri menapak/ pitunggua, kaki kanan diagonal kanan, tangan kanan lurus kedepan, tangan kiri samping kiri siku di tekuk ujung jari tangan kebawah dan digalatiak pergelangan tangan serentak pergelangan kaki ditarik dan gerakannya dibalas.

\subsection{Kalimat Gerak}

Kalimat gerak adalah kesatuan dari frase angkatan dan frase adalah yang merupakan satu rangkaian gerak yang sudah selesai dalam satu periode. Kalimat gerak bisa terdiri dari satu atau beberapa frase angkatan dan salah satu maka dari itu, untuk menentukan kalimat gerak sangat erat kaitannya dengan musik pengiring. Maka kalimat dalam hal ini dapat dikonotasikan seperti kalimat dalam bahasa atau kalimat lagu dalam karawitan.

Salah satu contoh Kalimat gerak pada tari Buai-Buai yaitu deskripsi gerak mamadek pamatang dengan Rentak kaki kanan serentak dengan putaran tangan kanan diikuti tangan kiri/tupai bagaluik, kaki kanan seret kekanan dan rentak dengan posisi kedua tangan disamping pinggul kanan, ujung jari tangan arahnya berlawanan, kaki kiri rentak ke kiri, kaki kanan tendang diagonal kanan, serentak pergelangan tangan dorong kedepan diagonal kiri, ujung jari tangan berlawanan.

\section{A. Frase Gerak}

Frase gerak merupakan kesatuan dari motif gerak yang dikembangkan baik dengan pengulangan maupun divariasikan, frase gerak bisa terdiri dari satu motif gerak atau beberapa motif gerak. (Suharto 1983:18) salah satu contoh deskripsi gerak rantak tumit kaki pada frase gerak tari Buai-Buai di Lubuk Lintah adalah menggunakan level tinggi, posisi berdiri dengan kaki pitunggua, tumit kaki kiri merantak dibelakang kaki kanan, dengan posisi tumit kaki kanan menapak didepan kaki kiri, ujung kaki kanan hadap keatas, kemudian gerakannya dibalas dengan kaki kanan lagi yang merantak.

\section{B. Motif Gerak}

Suatu tari pada dasarnya merupakan rangkaian dari tataran gerak yang meliputi satuan gerak yang paling kecil sampai pada satuan gerak yang paling besar, tataran gerak yang terkecil disebut motif gerak. Soeharto (1983:18) menjelaskan bahwa motif gerak adalah satuan atau unsur komponen yang terkecil dari sebuah tari.

Pada tari Buai-Buai dapat kita berikan pada salah satu contoh deskripsi gerak galatiak di motif gerak tari Buai-Buai yang berada di Lubuk Lintah adalah dengan galatiak pergelangan tangan yaitu telapak tangan hadap atas, seluruh jari diputar dari atas dibawa kebawah 
dan sesampai jari diatas langsung pergelangan tangan digalatiak.

\section{KESIMPULAN}

Keindahan telah menjadi bagian manusia yang mendunia. Keindahan pun telah menjadi kesadaran yang menyertai pertanyaan-pertanyaan tentang terciptanya kosmos dan perenungan mengenai Mahakuasa. Takdirnya bersifat absolut seiring dengan kehadiran manusia itu sendiri. Seiring perjalanan waktu cara manusia memandang keindahan pun mengalami pematangan dan pendalaman sehingga menumbuhkan getar-getar filosofis yang memiliki keterkaitan dengan hampir semua aspek kehidupan.

Tari Buai-Buai yang berkembang di daerah Lubuk Lintah, merupakan perluasan dan perkembangan dari daerah aslinya yaitu kanagarian Pauh. Di Lubuk Lintah gerakan dasar Tari BuaiBuai hanya memiliki dua gerakan, yakni gerakan dasar Buai-Buai dan gerakan dasar rantak kudo. Gerakan Buai-Buai merupakan cerminan atau pragmen gerak mengasuh anak. Gerak ini menjadi dasar gerak silat yang dilaksanakan dengan cara kaki kanan melangkah kekanan diikuti kaki kiri membentuk pitunggua. Tangan kiri melengkung di depan badan dan tangan kanan melengkung di sisi badan kanan. Kesan yang ditonjolkan pada gerakan ini adalah menghindari serangan dan mengambil ancang-ancang untuk melaksanakan suatu aksi.

Gerakan kedua adalah gerakan rantak kudo, gerakan ini mempunyai karakteristik dinamika gerak dengan cara kaki kiri menghentak dibelakang kaki kanan sementara kaki kanan terangkat, dan sebaliknya ketika kaki kiri menghentak di belakang kaki kanan kaki kiri terangkat. Sedangkan kedua tangan melakukan gerakan kesamping kiri dan kanan di depan dada. Dinamika gerak ini mencerminkan gerak tertatihtatih mengemban beban. Gerakan lainnya adalah gerakan-gerakan orang pergi ke sawah, dari gerakan mencangkul, menuai padi sampai menarik padi sebagai hasil panen. Tarian ini diiringi oleh gendang, saluang pauah, pupuik batang padi, talempong dan dendang.

Kajian ini mencoba mengamati bentuk struktur dan setetika tari Buaibuai Lubuak Lintah. Menulis kajian ini merupakan pengalaman yang memperkaya khasanah penulis dalam melihat bahwa di Minangkabau masih banyak tari tradisional yang masih mempertahankan pola-pola budaya tradisi dalam penyajiannya. Sehingga nilai- estetika tarian Minangkabau yang terletak pada gaya tari yang berakar pada ketangkasan dan kewaspadaan dapat diperlihatkan. Keberadaan dan perkembangan tari Buai-Buai yang dilakukan di Perguruan Singo Barantai mendapatkan pandangan khusus dari nilai estetika di mata masyarakat luas serta mampu menjadikan tari Buai-Buai sebagai destinasi Pariwisata di Sumatera Barat.

Harapan penulis semoga kajian ini dapat bermanfaat nantinya bagi generasi mendatang untuk mengetahui, bahwasannya banyak kesenian-kesenian tradisi Minangkabau, baik itu tari, musik dan jenis kesenian lainnya yang meiliki 
nilai estetika tinggi dan merupakan penggambaran dari pola kehidupan.

\section{DAFTAR PUSTAKA}

Astuti, Fuji. (1998), "Tari Buai-Buai Pada Masyarakat Desa Pauah Suatu Tinjauan Historis dan Struktural", Padang: Institut Keguruan dan Ilmu Pendidikan Padang.

Citrawati, A.A.I.A. (2015), "Estetika Tari Piring Lampu Togok di Desa Gurun Bagan Kelurahan VI Suku Solok Sumatera Barat", Tesis. Padang Panjang: ISI Padang Panjang.

Arikunto, Suharsimi. (2013), Prosedur Penelitian Suatu Pendekatan Praktik, Jakarta: Rineka Cipta.

Djelantik, A.A.M. (1999), Estetika Sebuah Pengantar, Bandung: Media Abadi.

Furchan, Arief. (1992), Pengantar Metoda Penelitian Kualitatif, Surabaya: Usaha Nasional.

Finoza, Welia. (2014), "Estetika Tari Putri Tujuh di kota Dumai Provinsi Riau", Padang Panjang: Tesis. ISI Padangpanjang.

Hadi, Y. Sumandiyo. (2012), Koreografi Bentuk- Teknik, Yogyakarta: Cipta Media.

Indrayuda, (2000), Eksistensi Tari Minangkabau, Padang: UNP Press.

Krisniawati, Neni. (2016), "Estetika Tari Lilin Bepinggan pada Masyarakat Kayu Agung Kabupaten Ogan Komering Ilir Provinsi Sumatera Selatan", Tesis. Padang Panjang: ISI Padangpanjang.

Kartika, Dharsono Sony. (2007), Estetika, Bandung: Rekayasa Sains.

Miles, Mathhew dan Huberman, Michael. (2014), Analisa Data Kualitatif, Jakarta: Universitas Indonesia Press.
Moleong, Lexy J. (2007), Metodologi Penelitian Kualitatif, Bandung: PT. Remaja Rosdakarya.

Rahayu, Gusti. (2017), “Estetika Tari Somba Siriah di Lubuk Jambi Kabupaten Kuantan Singingi Provinsi Riau", Tesis. Padang Panjang: ISI Padangpanjang.

Sachari, Agus. (2002), Estetika, Bandung: ITB.

Smith, Jacqueline. (2002), Komposisi Tari Petunjuk Praktis Bagi Guru, Jakarta: Balai Pustaka.

Soedarsono, RM. (1997), Tari-Tarian Indonesia I, Jakarta: Direktorat Jendral Kebudayaan, Departemen Pendidikan dan Kebudayaan.

SP, Soedarso, (2001), Kreatifitas Seni Pertunjukan Indonesia, Seminar Internasional Seni Pertunjukan Indonesia 24-25 Juli 2001. Surakarta: STSI Surakarta.

Strauss, Levi. (2006), Strukturalisme dan Teori Sosiologi, Yogyakarta: Pustaka Belajar.

Sumardjo, Jakob. (1999), Filsafat Seni, Bandung: ITB.

Sukmadinata, Nana Syoadih. (2009), Metode Penelitian Pendidikan, Bandung: PT. Remaja Rosdakarya.

Sugiyono. (20140, Metode penelitian Kombinasi (Mixed Methods), Bandung: Alfabeta.

Susanti, Meri. (2015), “Konsep Main Bungo dalam Pertunjukan Galombang Duo Baleh di Nagari Pitalah Kabupaten Tanah Datar Sumatera Barat".Tesis. Padang Panjang: ISI Padangpanjang.

\section{DAFTAR INFORMAN}

Dr. Fuji Astuti., M.Hum., 55 tahun, Dosen UNP Padang

Irwandi, M.Sn., 35 tahun, Seniman/Pelatih silat dan Pelatih Tari Buai-Buai di Perguruan Singo Ba- 
rantai Lubuk Lintah Padang, Dosen Unand Padang

Mirmaneli, 47 tahun, Ibu Rumah Tangga
Afrijhon, 47 tahun, Seniman

Meli M.S., 21 tahun, Seniman/ Penari 